\title{
THE SURGICAL TREATMENT OF PULMONARY STENOSIS*
}

\author{
BY \\ SIR RUSSELL BROCK \\ From Guy's Hospital and the Brompton Hospital \\ Received March 25, 1961
}

This lecture is based on a review of my experiences in the treatment of 198 patients with pulmonary valve stenosis, a condition that has occupied a great deal of my attention during the last twelve years. I hope that it will be of value to you even though it deals with a subject with which we are all familiar today. The term pulmonary stenosis is, of course, a generic one for all types of the condition and I propose to confine my remarks to pulmonary stenosis with an intact ventricular septum.

Incidence of Pulmonary Valve Stenosis. This brings me at once to an important fact that until the advent of pulmonary valvotomy pulmonary valve stenosis was thought to be exceedingly rare. As recently as 1947 Taussig wrote that she had never had the opportunity of studying a proven case and that her clinical description had, therefore, to be based on reports. How scanty these were is shown by Greene et al. who, in 1949, stated that they could find only 68 examples. Abbott in her analysis of 1000 cases of congenital heart disease studied at necropsy, reported 25 examples of which 6 had a persistent foramen ovale.

The rapid recognition of cases following the introduction of operations on the heart is illustrated by Campbell's observation in 1953 that 1130 cases of congenital heart disease seen in his clinic at Guy's Hospital included 116 cases of pulmonary valve stenosis (an incidence of 10 per cent): in the same group were 104 cases of persistent ductus arteriosus. I would think that even today the incidence of these two conditions is roughly equal. Wood (1950) gives the incidence as 14 per cent of all cases of congenital heart disease.

\section{Pathological Anatomy}

The association with other congenital abnormalities admits of no other conclusion than that pulmonary valve stenosis is itself a developmental lesion. Thus, with it in this series $I$ have seen the following 14 malformations.

(1) Bicuspid pulmonary valve.

(3) Persistent ductus arteriosus.

(5) Persistent foramen ovale with anomalous pulmonary veins.

(7) Atrial septal defect of secundum type.

(9) Either or both with anomalous pulmonary veins.

(11) Small or severely stenosed pulmonary valve ring.

(13) Small or semi-rudimentary right ventricle.
(2) Infundibular stenosis.

(4) Persistent foramen ovale.

(6) Atrial septal defect of primum type.

(8) Primum and secundum atrial septal defects together.

(10) Left-sided superior vena cava, with or without anomalous pulmonary veins.

(12) Small pulmonary trunk.

(14) Tricuspid valve stenosis.

The possible co-existence of any one of these lesions with pulmonary stenosis clearly has an important bearing on surgical treatment. Especially important are the varieties of atrial communication, although a simple persistence of the foramen is the commonest. The frequency of associ-

* The St. Cyres Lecture, 1960, with a few additions. 
ated anomalous pulmonary veins has emerged owing to the closer examination possible at open heart surgery. All these conditions have been dealt with at the same time as the valvotomy.

The fused valve cusps vary considerably in appearance. The occasional presence of a bicuspid valve has been mentioned. More usually three cusps are seen: they may be evenly fused to give a central orifice of varying size, or the commissures may be fused unequally to give a comma-shaped or more irregular orifice. The result is a fibrous diaphragm obstructing the emptying of the right ventricle and clearly presenting a challenge to surgery for its relief. In severe cases the valve orifice may be very small, especially when seen in a formalin-hardened specimen. Open operations have, however, revealed that the valve opening is usually larger than is thought. Campbell (1960) has recently written on this matter and he finds on theoretical grounds also that the orifice is larger than ordinarily supposed. Full details of his observations are in his article but, put briefly, assuming that the shape of the orifice is a rough triangle or a circle based on a triangle, the opening in adults can be rather more than $1 \mathrm{~cm}$. along each side of the triangle in mild cases, and rather less in average cases. In severe cases the opening is usually more nearly circular and about $0.6 \mathrm{~cm}$.$0.5 \mathrm{~cm}$. An orifice of $0.4 \mathrm{~cm}$. in an adult would be extremely severe and in the last stages.

The fused valve cusps may be thin or may be very thick and rigid, even in young patients. Myxomatous swelling is sometimes seen, although less often than in aortic valve stenosis; fibrous nodules are common on the margins of the orifice in older patients. The fused cusps usually form a dome or a low cone: a long cone is less often seen.

The post-stenotic dilatation of the pulmonary trunk is now well-recognized and understood and its value in radiological diagnosis is appreciated. It is less often known that the pulmonary valve ring and pulmonary trunk may be small and underdeveloped even though the vessel may show some post-stenotic dilatation. This again is of practical surgical importance as some stenosis, at least temporary, must remain at the valve ring level even though a complete valvotomy is done.

A small or rudimentary right ventricle is a very rare associated lesion that I have seen only once. Tricuspid valve stenosis is somewhat less rare and must always be thought of and sought for.

These lesions are primary anatomical ones. Of great importance are the secondary changes that occur in the pathological anatomy of the right ventricle itself. In mild stenosis what can be described as benign enlargement or compensatory hypertrophy is seen, but with more severe stenosis significant and even sinister changes occur in the myocardium. The thick large ventricle undergoes replacement fibrosis, loses its suppleness and becomes rigid, and the hypertrophic changes in the outflow tract cause secondary infundibular stenosis additional to the valvar stenosis. The nature and significance of these changes will be discussed later.

\section{The Clinical Significance or Length of Survival}

A true assessment of the life history of pulmonary valve stenosis is difficult and must always be so now that the natural course is affected by operation. Moreover, the recognition of the disease, for all practical purposes as recently as only 12 years ago, leaves us no earlier studies of longevity. We are compelled to fall back on a consideration of the age and clinical condition of patients coming for treatment or observed at autopsy. The age distribution in the 198 patients I have operated on is given below. It will be seen that 182 patients were below the age of 30 and only 16 were over 30 years: the two over 40 were 42 and 45 years.

$$
\text { Under } 10 \text { years, } 56 \quad \text { from } 21 \text { to } 30 \text { years, } 41 \text { from } 41 \text { to } 50 \text { years, } 2
$$

from 11 to 20 years, 85

from 31 to 40 years, 14

It is difficult not to attach significance to these figures which suggest that few patients survive beyond the age of 30 . It is, of course, possible that a substantial number of these younger patients might survive to the third or fourth decades without operation.

Also, presumably the cardiologists who referred these cases to me for operation must have a number of cases of lesser severity which they consider are not in need of operation, at any rate at present. I have no means of knowing how numerous such cases are although from time to time I see patients in whom the pulmonary stenosis is very mild and who may well never need an operation. 
Campbell and Missen (1959) have recently considered the long survival patients with pulmonary valve stenosis and mention that Abbott (1936) found the mean age at death in 25 recorded cases to be 19 years, while in 47 cases reviewed by Greene et al. (1949) it was 23 years. Campbell (1954) found it to be 20 years in a personal series of 14 patients.

Campbell and Missen record the case of a patient who lived until 68 years of age with pulmonary valve stenosis of moderate severity. They found reports of five patients who lived longer than this, the oldest being 75 . Their survey led them to the very reasonable conclusion that the size of the pulmonary valve orifice is the prime factor determining the length of life. From a comparison of the size of the valve orifice in the longer-lived group with the shorter-lived group of 14 cases reported earlier by Campbell they observed that the cross-sectional area of the valve orifice at necropsy in the long-lived group was approximately four times that of the short-lived group. The mean heart weight also was greater in the latter group. Presumably the right ventricular pressure would have been correspondingly higher in the younger group and lower in the older group.

That a critical stage of the disease is commonly reached by the third decade is certainly borne out by the clinical state of patients seen in the late twenties. Most of these exhibit stigmata to indicate that severe disability and death are approaching.

\section{THE INDICATIONS FOR OPERATION}

The basic indication for operation is to relieve the obstructed right ventricle of the strain that it is bearing, and our appraisal of each case, by both clinical and laboratory methods, should be directed towards assessing this strain. The presence of actual symptoms is only important in so far as they may serve as an indication of the degree of ventricular strain or of the severity of the obstruction.

Within this matter of the assessment of ventricular strain lies the bedrock of much of cardiac surgery. For many years I have taught that one of the basic functions of a cardiac surgeon is to relieve obstruction and in this he is strictly in accord with the general principles of surgery as seen in the need for relief of obstruction of any hollow viscus or duct in the body. I have been strongly criticized for this teaching. Nevertheless, I have no fear in continuing to emphasize it for I know it is right.

As general surgeons and physicians we have learned much about the relief of obstruction during the last 100 years, since Lister's discoveries enabled abdominal surgery to develop. We know that the sooner an obstruction is relieved, the lower is the mortality and the morbidity; and that the longer it is allowed to continue, the higher are the mortality and the morbidity, and this is brought about by various secondary changes.

There is no need in this company to detail the features that should serve us in the assessment of the ventricles. A raised venous pressure or palpable hypertrophy of the right ventricle are certainly significant. The electrocardiogram is obviously of paramount importance, although it is not very informative in right ventricular pressures up to $60 \mathrm{~mm}$. $\mathrm{Hg}$. I wish only to say a few special words about the level of right ventricular pressure and about radiological appearances.

The Right Ventricular Pressure. It is human to ask for a "sign" and the sign often requested in pulmonary stenosis is the level of right ventricular pressure that demands operation.

In the earlier days of valvotomy a higher figure was given, but it soon became customary to advise operation with a right ventricular pressure of $75 \mathrm{~mm}$. $\mathrm{Hg}$ or over. Some surgeons then began to accept patients with a lower pressure, e.g. $60 \mathrm{~mm}$. Hg. In this way one can soon enter the field of doubtful indication for operation. Happily recent observations of the ventricular pressure during exercise, as well as at rest, have clarified the situation considerably. Briefly a right ventricular pressure of $60-70 \mathrm{~mm}$. $\mathrm{Hg}$ at rest will about double itself on exercise. Thus, if it is known that during any effort or excitement the right ventricle is exposed to a pressure of 120 $150 \mathrm{~mm} . \mathrm{Hg}$ there will be little hesitation about advising valvotomy. When the pressure at rest is over $120 \mathrm{~mm}$. $\mathrm{Hg}$ it will perhaps not double on exertion, but it very nearly does so. 
Radiology. The information given by radiology in regard to the overload the right ventricle is suffering is often small. The concentric hypertrophy of the muscle is usually hidden within the heart shadow and any enlargement of the heart outline is more likely due to the right atrium. It is important to realize that in pure stenosis cardiac enlargement is small and that any notable increase in size is an indication of ventricular failure. Symptoms may be severe, or sudden death may occur, when radiologically the heart is but little enlarged. Occasionally a very large heart is seen and this must indicate very advanced disease: it carries a high operative risk and an indifferent prognosis even when operation is survived.

Electrocardiogram. More informative and more sensitive than radiology is the electrocardiogram, but even this may not be helpful in right ventricular pressures up to $60 \mathrm{~mm}$. $\mathrm{Hg}$. When $\mathrm{T}$ wave changes are present in the right ventricular chest leads the ventricle is certainly under undesirable strain that must be relieved. $T$ wave inversion and $S-T$ depression may extend right across the chest leads as far as V6; in such cases the right ventricular pressure is usually between 150 and $250 \mathrm{~mm} . \mathrm{Hg}$. It is in these severe cases that radiological enlargement of the ventricle is seen, reflecting real failure and often irreversible damage to the myocardium.

\section{The Significance of Cyanosis}

Cyanosis has been of varying importance in this series; in the earlier cases it dominated the clinical picture. This can be seen from Table I which also gives the total incidence. In the first 50 cases, 35 were cyanosed and most were severely so. No doubt it was this feature that caused the earlier patients to be sent for treatment along with the general wave of blue patients, most of whom had Fallot's tetralogy. This blueness was a dominant feature and we found that it was also such a grave one that we made it a rule that no cyanosed patient with pulmonary valve stenosis should leave hospital without valvotomy. The mortality among cyanosed patients attending the Outpatient Clinic at one time reached 40 per cent.

TABLE I

INCIDENCE OF CYANOSIS

\begin{tabular}{ll|c|c}
\hline & & Cyanotic & Acyanotic \\
\hline Total cases (198) & $\ldots$ & $74\left(14\right.$ died $\left.^{*}\right)$ & $124(9$ died $)$ \\
First 50 cases .. & $\ldots$ & 35 & 15 \\
First 100 cases & $\ldots$ & 52 & 48 \\
Last 50 cases .. &. & 8 & 42 \\
\hline
\end{tabular}

* If first 7 operations (with 6 deaths) are omitted, 8 died.

As time went on the proportion of cyanosed patients lessened; thus in the first 100 cases 52 were blue. In the last 50 cases, only 8 were blue. It also emerged that the presence of cyanosis was not always as urgent as it had appeared to be earlier. Milder cases were seen who had been moderately blue for years and seemed little the worse. It would, therefore, seem that the urgency of each case must be assessed separately on general criteria and not primarily by cyanosis.

The increased diagnosis of non-cyanosed cases is due to our greater knowledge of congenital heart disease. Formerly it needed a leading feature such as cyanosis to separate out a case, especially as symptoms in the non-cyanosed patients are often trivial. Their severity is now more widely appreciated and recognized.

Although the cyanosed patient is less common, and not always urgent, he may still present as an important problem in diagnosis and management. The similarity to Fallot's tetralogy may be very close and although today, with the varied methods of differentiation at our disposal, confusion should rarely arise, there are still occasions when the diagnosis is only revealed at cardiotomy. 
In infants and young children this confusion with Fallot's tetralogy, or with other cyanotic heart conditions, may be especially dangerous if the urgent need for operation is not recognized. In an infant who is blue from Fallot's tetralogy operation may often be wisely postponed until he is older. If, however, the infant is blue from pulmonary stenosis with a reversed atrial shunt, the condition is always urgent and must be treated immediately by operation. The mortality in infants who do not have relief of their stenosis is very high, and in many the correct diagnosis is never made. The fact that an opportunity has been lost of saving life and virtually curing the heart condition may pass unrecognized. Some of our most dramatic and successful results have been gained in this group.

The cause of cyanosis in association with pulmonary valve stenosis with a normal aortic root is a right-to-left shunt through a communication between the right and left atrium. The term "communication" is used deliberately in preference to "atrial septal defect" because in the large majority of such cases the right-to-left shunt occurs through an unsealed foramen ovale which, although stretched and rendered incompetent by the high pressure in the right ventricle and right atrium, still retains the ability to recapture its valvular action when the obstruction to the emptying of the right heart is relieved. I have been impressed by the fact that after valvotomy alone the cyanosis is almost invariably relieved immediately and completely-even dramatically. Closure of the communication has seldom been necessary.

If the defect is large and non-valvular it is almost inevitable that left-to-right shunting will occur when the stenosis is relieved and that the features of pulmonary plethora due to an atrial septal defect will develop. This has occurred only three times in this series: a true atrial septal defect has been observed in nine cases and has been closed at the time of the valvotomy. More usually when a true atrial septal defect has been present the left-to-right shunt has been dominant from the first and the patient has not been cyanosed.

Of course, in all cyanosed cases a digital exploration should be made through the right atrial appendage to assess the size and nature of the communication. With an open heart technique most surgeons prefer to close the communication unless it be a very small valvular one. In the 62 cyanosed patients I have treated by closed valvotomy, cyanosis was completely, and usually immediately, relieved in all but 3 or 4 patients. In one in whom cyanosis persisted, even though in a greatly lessened form, the subsequent clinical, catheterization, and operation findings were particularly instructive.

A.F., a man aged 22, was first seen in 1952 with a history of cyanosis since the age of 5 years. Cyanosis was grade 3 and finger clubbing was grade 4; the red cell count was 7 million, hæmoglobin 142 per cent. A clinical diagnosis of pulmonary valve stenosis with reversal of flow through a valvular foramen ovale was confirmed by both angiocardiogram and by cardiac catheterization. The systemic arterial oxygen saturation was 85 per cent; the right ventricular pressure was $105 / 0$.

Closed pulmonary valvotomy was performed on July 3, 1952; a good split was obtained. A pressure withdrawal record after valvotomy showed:
Pulmonary trunk $11 / 7 \mathrm{~mm}$. $\mathrm{Hg}$
Infundibulum $28 / 7 \mathrm{~mm} . \mathrm{Hg}$
Right ventricle $40 / 7 \mathrm{~mm} . \mathrm{Hg}$

He made a good recovery from operation and lost most of his cyanosis.

In December, 1959, he was examined by Dr. A. Leatham who referred him back as things were not fully satisfactory. Although the result continued substantially good and his colour was normal at rest he became blue (grade 2) on exercise and his finger clubbing was still grade 4. There was a minor $a$ wave in the neck; the liver was not enlarged. The right ventricle was impalpable; there was no thrill. A short pulmonary systolic murmur was followed by a single second sound; there was no diastolic murmur. The chest radiograph showed the lung vascularity was about normal; the cardiothoracic ratio was $12 / 28 \cdot 25$. The electrocardiogram was normal. Hæmoglobin was $16 \cdot 7$ g. $(114 \%)$.

Cardiac catheterization disclosed a systemic oxygen saturation of 96 per cent and no evidence of a shunt at rest, but after exercise the saturation fell to 79 per cent. The catheter passed through an interatrial communication. The relevant pressures were:

\begin{tabular}{|c|c|}
\hline Pulmonary trunk & $15 / 8 \mathrm{~mm}$ \\
\hline Left ventricle & $105 / 0 \mathrm{~mm} . \mathrm{Hg}$ \\
\hline Right atrium & $2 \mathrm{~mm} . \mathrm{Hg}$ \\
\hline
\end{tabular}

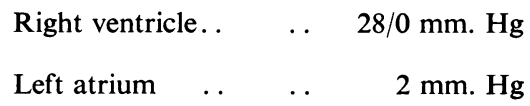


It seemed remarkable that with such apparent satisfactory relief of the valve stenosis reversed shunting occurred on exercise.

Open exploration under extracorporeal circulation was done on October 17, 1960. There was no evidence of anomalous pulmonary venous drainage, which had seemed a possibility. Digital exploration of the right atrium revealed a valvular patency of the foramen ovale which admitted the index finger sufficiently to identify the normal entry of the pulmonary veins into the left atrium.

There was no external evidence of residual pulmonary stenosis and needle pressures were:

Pulmonary trunk $30 / 20 \mathrm{~mm}$. Hg Right ventricle $30 / 5 \mathrm{~mm} . \mathrm{Hg} \quad$ Brachial artery $\quad 120 / 90 \mathrm{~mm}$. Hg

The foramen ovale was closed by two sutures. A finger passed through the tricuspid valve into the pulmonary outflow disclosed that the pulmonary valve orifice was about $1.2 \mathrm{~cm}$. in diameter. The valve was exposed and was seen to be bicuspid; each commissure was divided for about $3 \mathrm{~mm}$. and this enabled the index finger to pass freely into the ventricle. The final pressures were:

Pulmonary trunk $30 / 20 \mathrm{~mm}$. Hg Right ventricle $40 / 10 \mathrm{~mm} . \mathrm{Hg} \quad$ Brachial artery 120/90 mm. Hg

He made a smooth surgical recovery and lost all cyanosis.

It seems remarkable that such a trivial residual pulmonary stenosis could be associated with cyanosis; it suggests that an important additional factor was diminished diastolic filling power of the right ventricle.

Late investigation of one other patient since this case supports the view that it is preferable to close the atrial communication whenever possible; certainly in the presence of cyanosis.

A.C., aged 5, presented in 1953 with severe pulmonary valve stenosis and with cyanosis from a reversed interatrial shunt. Cyanosis and clubbing were both grade 4.

The electrocardiogram showed severe right ventricular hypertrophy with $\mathbf{S}-\mathrm{T}$ depression and steep $\mathrm{T}$ inversion across all the chest leads.

Closed valvotomy was done in December, 1953, a typical severe valve stenosis being found. - Pressure withdrawal records before and after valvotomy showed that the pressure in the pulmonary trunk rose from $11 \mathrm{~mm}$. to $25 / 6 \mathrm{~mm}$. and that in the right ventricle fell from $105 / 35$ to $43 / 13 \mathrm{~mm}$. Hg. There was dramatic and immediate relief of the cyanosis.

She was reviewed in September, 1960, now aged 12 years. Her parents considered her normal. There was, however, slight cyanosis. The electrocardiogram showed striking improvement, right ventricular hypertrophy being slight with $\mathrm{T}$ inversion in only V1 and V2.

Cardiac catheterization in November, 1960, showed the systemic arterial oxygen saturation at rest was 90-93 per cent. There was clearly a small $(0.5$ 1.) right-to-left shunt. A pressure withdrawal record showed the following pressures: pulmonary trunk, 19/6; infundibulum, 24/0; and right ventricle, 32/1 $\mathrm{mm}$. Hg.

The result from a closed valvotomy in 1953 is quite acceptable, especially considering the severity of the lesions. The superiority of an open operation with closure of the interatrial communication is, however, quite evident.

\section{The Treatment of Pulmonary Valve Stenosis}

Although many hundreds of operations have now been done for pulmonary valve stenosis, we still do not know the best procedure for all cases. In its simplest form pulmonary valve stenosis consists of a fibrous diaphragm formed by the fused cusps and with a small central orifice. Relief of this should be achieved by merely cutting open the fused cusps; this can give immediate, satisfactory, and lasting relief.

In the early days in 1948 we were more than content to achieve a safe and simple valvotomy. Indeed this was a notable surgical advance. However, nothing continues as simple as it first appears to be, and this has proved to be so with valvotomy for pulmonary stenosis. The valve stenosis sets in chain various secondary phenomena, especially affecting the ventricular musculature, and these constitute a complex surgical problem.

\section{Closed Pulmonary Valvotomy}

This operation is essentially simple in conception and consists of introducing a cutting valvotome through a small incision in the outflow tract of the right ventricle. This divides the valvar diaphragm transversely and the cut is then split wide open by an expanding dilator. The stenosed diaphragm 
is converted into a bicuspid valve. The operation can be performed quickly and simply and can give excellent results. The mortality is relatively low: thus in this series closed valvotomy was used in 114 cases with 14 deaths. The first 7 patients were severely ill, being in actual heart failure, and three of them died during induction of anæsthesia or as soon as the chest was opened: if these 7 are excluded, the mortality becomes 8 out of 107 patients. This compares reasonably with 5 deaths in 84 cases of open valvotomy.

The very satisfactory drop in right ventricular pressure that can be achieved with corresponding improvement in the pulmonary artery pressure is shown in Fig. 1. Fig. 2 shows strikingly how this

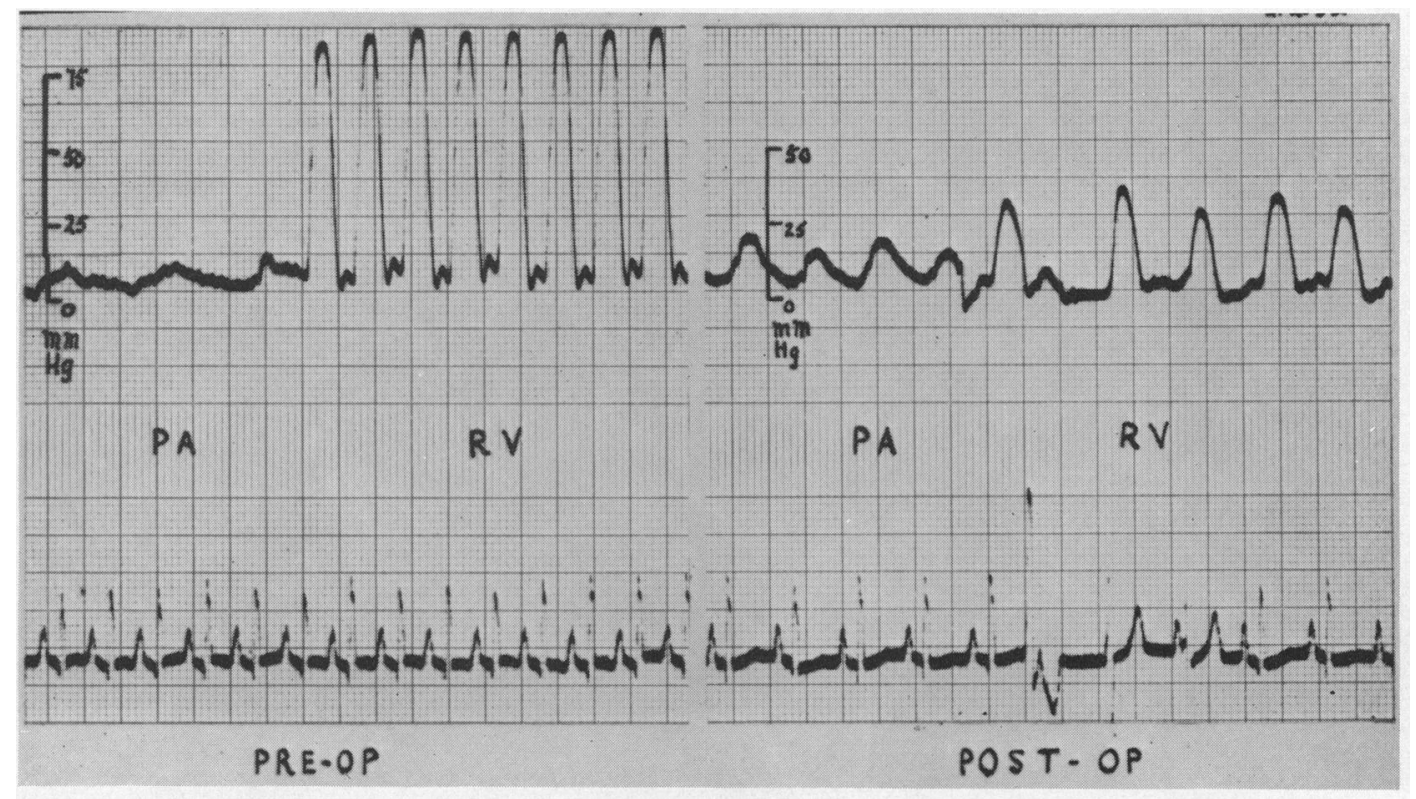

FIG. 1.-The immediate fall in right ventricular pressure following closed pulmonary valvotomy for pulmonary valve stenosis with a closed ventricular septum and a reversed interatrial shunt.

improvement may be reflected in the great diminution in size of the heart radiologically. The electrocardiogram also shows corresponding lessening or disappearance of the right ventricular hypertrophy and strain pattern.

It is unnecessary to weary you by a critical survey of the condition before operation and after operation in these 114 cases of closed valvotomy. Campbell (1959) has recently reported a critical follow-up of 64 patients ( 21 cyanotic and 43 acyanotic) who were the survivors of 76 operated on by me at Guy's Hospital. The average follow-up was 6 years. Campbell was able to report a complete follow-up of 57 patients and tried to decide how many of these had been improved enough to be regarded as normal for most purposes, with a normal outlook for the future. He found that in 35 $(61 \%)$ of the 57 the results were so good as nearly to reach this high standard. Another 22 patients $(39 \%)$ were improved, often greatly, but they still had significant pulmonary stenosis which may prove harmful in the future.

In the best results the average systolic gradient across the pulmonary valve was reduced from 111 to $28 \mathrm{~mm}$. $\mathrm{Hg}$. In the improved group the average gradient was reduced from 132 to $55 \mathrm{~mm}$. $\mathrm{Hg}$.

Although closed pulmonary valvotomy can give results that are reasonably good, it has now been almost entirely displaced by open valvotomy in conformity with the modern trend of cardiac surgery away from closed towards open procedures. There is still a place for the closed operation in bad risk cases, especially if cyanosis is severe. This applies particularly to severely ill infants 


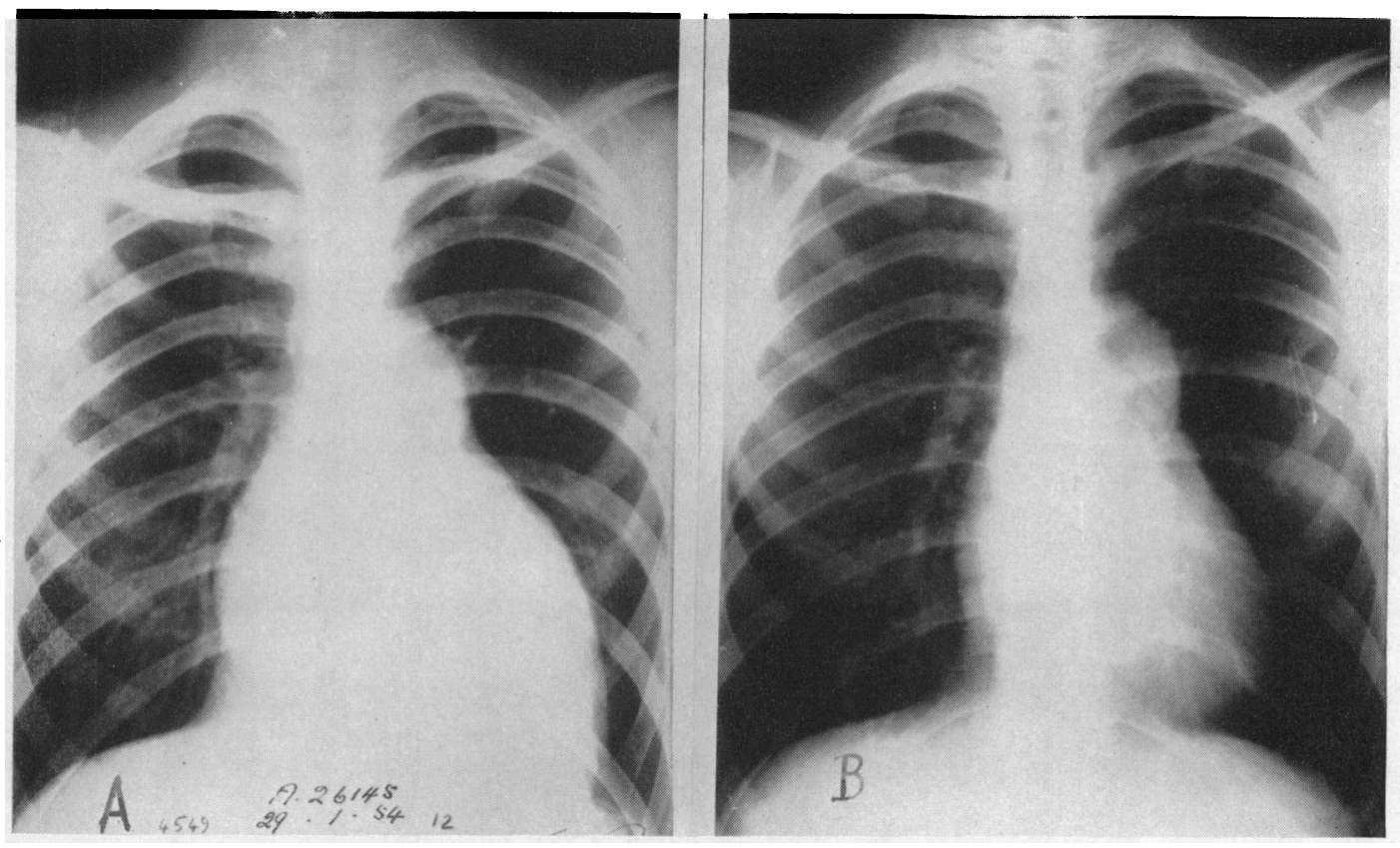

FIG. 2.-Striking diminution in size of the heart following closed valvotomy. (A) Before operation. (B) Two years after valvotomy.

and to the occasional older patients over 35 years of age. Potts (1959) has recently stated that he still prefers to use the transventricular closed operation for infants with a huge heart. Waterston (1960) tells me that this is also his practice.

I have noticed that after closed valvotomy in these infants there is a higher incidence of pulmonary regurgitation, a state that is ordinarily quite rare after a closed valvotomy. This is understandable in view of the small size and delicate nature of the infant valve. I am, therefore, impressed by Mustard's recommendation of using surface hypothermia in these infants, where cooling is easy and quick and allows an open precise valvotomy: he has operated on 17 infants in this way with only one death.

In older patients when the stenosis is severe so that there is a small central hole in a firm fibrous diaphragm, a closed valvotomy can give a large and satisfactory bicuspid opening. In less severe cases with a larger valve orifice and softer and more resilient cusps, it has no real place for it may fail to relieve the stenosis because the cusps are not really cut but give way in front of the instruments. Although Campbell found the result excellent in 61 per cent this proportion is not high enough. An open operation allows deliberate division of each commissure and can give complete relief of the valve stenosis in virtually all cases.

Hanson, Ikkos, Crafoord, and Ovenfors (1958) in reporting 28 of their own cases found that closed and open valvotomy gave equally good results. However, from a survey of 99 reported cases they found a significant difference in favour of open valvotomy.

\section{Open Pulmonary Valvotomy}

Open valvotomy through the pulmonary artery was first introduced by Varco (1951) who mentioned in the discussion of a paper by Merlin and Longmire (1951) that he had operated upon five patients with four successes. He produced inflow occlusion by clamping the venæ cavæ and did the open valvotomy within the three minutes of circulatory arrest this method permits. The estab- 
lishment of open pulmonary valvotomy is, however, usually attributed to Swan (Blount, McCard, Meuller, and Swan, 1954) who first used hypothermia to enable the inflow occlusion time to be prolonged to some 8-10 minutes thus making possible an unhurried and deliberate valvotomy.

There are still surgeons who favour a quick operation at normal temperature by using the single inflow occlusion introduced by Varco. Edwards (1960) has written on this and Lam (1960) is enthusiastic about it and has used it in 71 patients with only one death: he has used total by-pass in 9 cases with no deaths.

Most surgeons use either hypothermia or total heart-lung by-pass. There is little doubt that the use of total by-pass springs from the present popularity of heart-lung machines and because this particular operation carries a low mortality and helps to raise general morale in the difficult technique of total body perfusion. The use of total by-pass is not really necessary in all cases, for most can be readily and efficiently dealt with under hypothermia. Thus in my own series of 84 open valvotomies by-pass was used in only 13 cases. The whole procedure is much less complex with hypothermia; simpler apparatus, a smaller team, and much less blood are needed than if full body perfusion is used. The temperature need only be lowered to $31.5^{\circ} \mathrm{C}$. If an atrial septal defect co-exists this can be closed during a second period of circulatory arrest; and for this a temperature of $30.5^{\circ} \mathrm{C}$. is needed. In the presence of cyanosis, I prefer total by-pass.

Although the superiority of open valvotomy is unquestioned, it is interesting that one of the chief reasons originally urged for its use is largely erroneous. It was noted that after a closed valvotomy the pressure in the right ventricle might be lowered little or not at all. It was assumed that this was due to an essential inefficiency of closed valvotomy to relieve the stenosis completely. This, of course, can be true, and certainly may be true in the hands of an inexpert surgeon using incorrect instruments. It is also true that even when a completely efficient valvotomy has been performed, either open or closed, the pressure in the right ventricle may not be lowered. I emphasize that this may happen even when a complete valvotomy has been done as an open procedure. Two examples of this can be seen in Table II.

TABLE II

Failure to Relieve Raised R.V.P. by Valvotomy

\begin{tabular}{lll|l|l}
\hline & & & P.A. & R.V. \\
\hline Before valvotomy &. &.. & 13 & $167 / 23$ \\
After valvotomy &. &.. & $12 / 9$ & $151 / 15$ \\
\hline Before valvotomy &. &. & $20 / 10$ & $80 / 10$ \\
After valvotomy &. &. & $20 / 17$ & $70 / 5$ \\
\hline
\end{tabular}

The reason for this failure to convert the right ventricular pressure is now well understood and the mechanism is displayed in Fig. 3. It will be seen that it is due to the development of secondary muscular hypertrophy of the infundibulum consequent upon the severe stenosis. After valvotomy the tension in the ventricle is sufficiently relieved to allow the thickened walls of the infundibulum to come together in systole and so to constitute a secondary functional obstruction. It is rarely that true fibrous, infundibular obstruction co-exists: this is usually congenital but may also result from secondary fibroid changes in the infundibular muscle producing rigidity and thus fixed narrowing.

This condition was recognized and the mechanism of its production described by Connolly, Lev, Kirklin, and Wood (1953) and independently by me in 1955 (Brock, 1955). Its recognition and understanding has been an important advance in our knowledge of pulmonary stenosis. It serves as an excellent example of the fact that when an obstruction is allowed to continue unrelieved, various important secondary changes occur that result in the condition being no longer quickly and totally curable by simple relief of the obstruction. Johnson (1959, $a$ and $b$ ) has made 

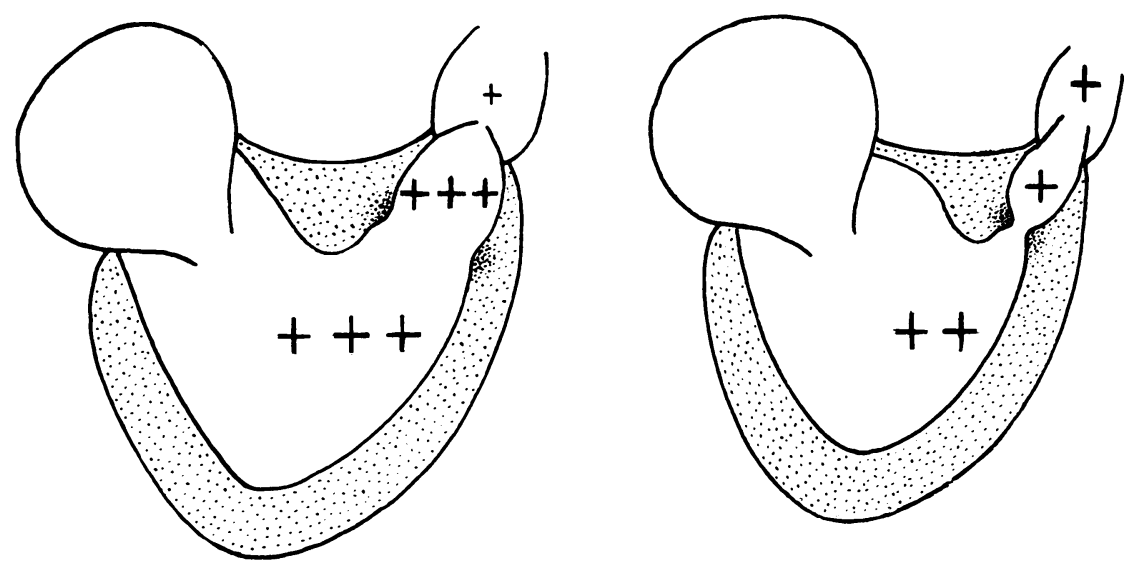

FIG. 3.-Diagram to show the mechanism of production of secondary infundibular stenosis after pulmonary valvotomy.

important contributions to the physiology and mechanics of this hypertrophic infundibular obstruction in his careful and valuable work recently published.

The problem of pulmonary valvotomy for pulmonary stenosis cannot be efficiently presented without a detailed consideration of secondary infundibular stenosis. This is especially so because a first consideration of the condition prompts the surgeon to remove this infundibular stenosis when it is recognized. Indeed, this is the most usual recommendation today.

The effect of secondary excision of the infundibular obstruction, after valvotomy has failed to lower the right ventricular pressure adequately, is shown in Table III. It is easy to be influenced

TABLE III

Conversion of Persistent High R.V.P. by Infundibular Resection

\begin{tabular}{llll|l|c|c}
\hline & & & & P.A. & R.V. \\
\hline Before open pulmonary valvotomy & $\ldots$ & $\ldots$ & $\ldots$ & $34 / 18$ & $135 / 8$ \\
After open pulmonary valvotomy & $\ldots$ & $\ldots$ & $\ldots$ & $23 / 10$ & $120 / 10$ \\
After open infundibular resection &. & $\ldots$ &. & $18 / 12$ & $28 / 6$ \\
\hline
\end{tabular}

by a result such as this and accept that infundibular resection should always be used in such cases. Greater experience teaches that it is not always so effective as is shown by Table IV.

TABLE IV

Failure to Convert Persistent High R.V.P. by Infundibular Resection

\begin{tabular}{llll|l|l}
\hline & & & & P.A. & R.V. \\
\hline Before open pulmonary valvotomy & $\ldots$ & $\ldots$ & $\ldots$ & $18 / 0$ & $150 / 0$ \\
After open pulmonary valvotomy & $\ldots$ & $\ldots$ & $\ldots$ & $25 / 10$ & $170 / 0$ \\
After open infundibular resection & $\ldots$ & $\ldots$ &.. & $30 / 15$ & $160 / 0$ \\
\hline
\end{tabular}

In this case open resection of the infundibular stenosis has failed to lower the right ventricular pressure. This is not entirely surprising seeing that the remaining hypertrophied muscle of the 
infundibulum can still contract down in systole and maintain the obstruction. Indeed, it would seem fundamentally an unphysiological and unsurgical procedure to resect hypertrophied muscle in this way. Happily Nature comes to our help and with the relief of the valve stenosis the right ventricular hypertrophy gradually regresses and with it the muscular infundibular obstruction. Thus after a year or two, the right ventricular pressure can fall to normal. Table $\mathrm{V}$ completes the story begun in Table IV, in which it will be seen that the right ventricular pressure ultimately fell to normal in two patients.

TABLE V

Spontaneous Regression of High R.V.P. AFTer Infundibular ReSection had Failed. Two CASES

\begin{tabular}{|c|c|c|c|c|c|}
\hline & & & & P.A. & R.V. \\
\hline $\begin{array}{l}\text { Before open pulmonary valvotomy } \\
\text { After open pulmonary valvotomy } \\
\text { After open infundibular resection } \\
21 \text { months later } \quad .\end{array}$ & $\begin{array}{l}\cdots \\
\cdots \\
\cdots\end{array}$ & $\begin{array}{l}\cdots \\
\cdots \\
\cdots \\
\cdots\end{array}$ & $\begin{array}{l}\cdots \\
\cdots \\
\cdots\end{array}$ & $\begin{array}{l}18 / 0 \\
25 / 10 \\
30 / 15 \\
16 / 5\end{array}$ & $\begin{array}{l}150 / 0 \\
170 / 0 \\
160 / 0 \\
30 /-2\end{array}$ \\
\hline $\begin{array}{l}\text { Before open pulmonary valvotomy } \\
\text { After open pulmonary valvotomy } \\
\text { After open infundibular resection } \\
18 \text { months later } \quad . . \quad \text {.. }\end{array}$ & $\begin{array}{l}\cdots \\
\cdots \\
\cdots\end{array}$ & $\begin{array}{l}\cdots \\
\cdots \\
\cdots \\
\cdots\end{array}$ & $\begin{array}{l}\cdots \\
\cdots \\
\cdots\end{array}$ & $\begin{array}{l}16 / 0 \\
23 / 10 \\
18 / 10 \\
23 / 11\end{array}$ & $\begin{array}{c}180 / 20 \\
120 / 10 \\
110 / 12 \\
25 /-1\end{array}$ \\
\hline
\end{tabular}

It would be possible to give many examples of this but there is no need today now that the phenomenon is widely recognized.

Bromley (1958) has pointed out that if the right ventricular pressure is again taken some 20-30 minutes after valvotomy it will be found to have dropped to a lower level. I have not been able to confirm this as a general rule on cases I have observed. Kittle et al. (1960) have shown by postoperative monitoring of the right ventricular pressure by a venous catheter left in situ for several days that the pressure remains raised and may even rise further.

The present surgical recommendation to resect the infundibular stenosis in every case of uncorrected right ventricular pressure introduces a matter of fundamental importance that must be fully and critically discussed.

\section{Should Routine Open Resection be Performed for Secondary Hypertrophic Infundibular Stenosis?}

The recommendation of routine open resection of the hypertrophic infundibular stenosis whenever the right ventricular pressure remains high is based on the premise that it is dangerous and often fatal to leave the right ventricle carrying the burden of a severe residual obstruction during the post-operative period. On first principles it must be better to relieve the right ventricle of any such burden. This recommendation of routine resection of the infundibulum is, however, based on what are said to be two absolute equations, that residual high R.V. pressure means death, and that corrected R.V. pressure means survival.

I feel that these premises are false and that the problem must include other factors that cannot be lightly ignored. Thus, I suggest the true presentation is that a residual high R.V. pressure plus a weak state of myocardium plus an incision in the R.V. wall mean death.

In other words a residual high right ventricular pressure is only one factor in determining death or survival. The essential thing is the efficiency of the myocardium. It may well be able to tolerate a residual high pressure (Tables IV and V), but is less likely to do so if it is in a weak state before, and especially if its efficiency has been further impaired by an incision. On the other hand, even if the R.V. pressure has been reduced by an effective relief of the obstruction, the patient may still 
die because of the inability of a badly weakened ventricle to withstand the extra burden of the ventriculotomy. An example of this is shown in Table VI. The patient was aged 8 years and it will

TABLE VI

Death after Successful Pressure Conversion by Infundibular Resection

\begin{tabular}{lllll|l|l|l}
\hline & & & & P.A. & R.V. \\
\hline Pressures before valvotomy & $\ldots$ & $\ldots$ & $\ldots$ & $\ldots$ & $34 / 18$ & $135 / 8$ \\
Pressures after valvotomy & $\ldots$ & $\ldots$ & $\ldots$ & $\ldots$ & $23 / 10$ & $120 / 10$ \\
Pressures after open infundibular resection & $\ldots$ & $\ldots$ & $18 / 12$ & $28 / 6$ \\
\hline
\end{tabular}

be seen that there was virtually no residual high R.V. pressure and yet she died of right ventricular failure 18 hours after operation.

Again, even with a free and open infundibular resection it may not be possible actually to achieve a satisfactory reduction of the R.V. pressure. This is shown in Table VII. The patient

TABLE VII

Death after FaIlure to CONVERT R.V.P. by INfundibular Resection

\begin{tabular}{lllll|l|l}
\hline & & & & P.A. & R.V. \\
\hline Pressures before valvotomy & $\ldots$ & $\ldots$ & $\ldots$ & $\ldots$ & $15 / 8$ & 5 (mean) \\
Pressures after open valvotomy $\ldots$ & $\ldots$ & $\ldots$ & $\ldots$ & $150 / 15$ \\
Pressures after open infundibular resection & $\ldots$ & $\ldots$ & 5 (mean) & $90 / 0$ \\
\hline
\end{tabular}

was aged 5 years and died 36 hours after operation with frank right ventricular failure. Not only was his R.V. pressure not lessened adequately but his overworked ventricle had the extra burden of an incision.

It was the tragic experience in this case that turned me against the practice of performing routine open infundibular resection if the R.V. pressure remained high after the valve stenosis had been relieved. I feel confident, from my accumulated experience, that this child would not have died if the ventricle had not been opened. In other words death was due to over-treatment.

Within less than a month I was faced with a similar problem in a boy aged 11 years (Table VIII).

TABLE VIII

High Residual R.V.P. After Open Pulmonary Valvotomy

\begin{tabular}{|c|c|c|c|c|c|}
\hline & & & & P.A. & R.V. \\
\hline $\begin{array}{l}\text { Pressures before valvotomy } \\
\text { Pressures after open valvotomy } \\
30 \text { minutes later . . }\end{array}$ & $\begin{array}{l}\cdots \\
\cdots \\
\cdots\end{array}$ & $\begin{array}{l}\cdots \\
\cdots \\
\cdots\end{array}$ & $\begin{array}{l}\cdots \\
\cdots \\
\cdots\end{array}$ & $\begin{array}{l}8 / 2 \\
8 / 2 \\
8 / 2\end{array}$ & $\begin{array}{l}225 / 2 \\
280 / 8 \\
220 / 12\end{array}$ \\
\hline
\end{tabular}

This was clearly an alarming situation and, if you believe the simple equation above, is likely to prove fatal. However, with my faith in the more complex equation $I$ felt it was proper to take the calculated risk of leaving the infundibular stenosis. The patient made a good recovery and all features up to date (18 months after operation) indicate a steady conversion of the high R.V. pressure, as has occurred in so many other patients. It is as yet too early to obtain the exact pressure 
by cardiac catheterization. This patient, of course, had the features of substantial right ventricular overload in the days after operation but he was able to ride out of the storm.

Johnson (1959b) in his study of 75 of my cases at Guy's Hospital concluded that a persistently raised R.V. systolic pressure exceeding $100 \mathrm{~mm}$. $\mathrm{Hg}$ was associated in the post-operative period with a high morbidity and mortality. A phase of right ventricular failure in the post-operative period need not be serious if the patient does weather the storm and subsequently achieves spontaneous reduction of the R.V. pressure.

What we need to do is to examine more critically the actual mortality of these cases and also in what proportion imperfect conversion of pressure occurs. Thus Johnson suggests that the critical level is $100 \mathrm{~mm}$. $\mathrm{Hg}$ and that 3 out of 11 cases specifically studied to assess regression of infundibular stenosis showed incomplete regression. It has also been stated that patients over 20 years of age tolerate a high residual pressure badly and that age is an added indication for open infundibular resection. I can say at once that a study of my figures shows no corroboration of this. From the two cases just quoted (Tables VI and VII) it will be seen that younger children may certainly not survive valvotomy and secondary infundibular resection. Any patient aged 20 or over with severe pulmonary valve stenosis is almost certain to have an associated hypertrophic infundibular stenosis; he is also likely to have a right ventricle far less tolerant of an incision.

This problem of whether or not to resect a hypertrophic infundibular stenosis is of such great importance that I have made a fairly complete analysis of my own cases. Statistics are always tedious and I ask your patience while I try to present my findings, my justification being that this is perhaps the most important practical matter arising from this lecture.

That it is common enough to be important is shown by the fact that out of 162 of my cases with proper pressure observations, a significantly high residual R.V. pressure was present in 60 , that is 37 per cent. Johnson found a higher incidence $(77 \%)$ after open valvotomy than after a closed valvotomy $(51 \%)$. This is not entirely confirmed in my full series in which the incidence is:

$\begin{array}{llrllll}\text { Closed valvotomy } & \ldots & 78 & \text { residual R.V. pressure in } 35 & \ldots & (45 \%) \\ \text { Open valvotomy } . . & \ldots & 84 & \text { residual R.V. pressure in } 25 & \ldots & (30 \%) \\ \text { Both operations } \ldots & \ldots & 162 & \text { residual R.V. pressure in } 60 & \ldots & (37 \%)\end{array}$

It is not entirely satisfactory taking an arbitrary residual systolic R.V. pressure of $100 \mathrm{~mm} . \mathrm{Hg}$ as the dividing line because the pressures observed at operation are often much lower than at cardiac catheterization preceding operation. This is almost constant and in a typical case one may find:

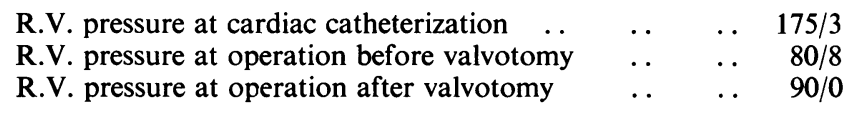

One must include such a case as an example of unsatisfactorily high residual right ventricular pressure even though the final pressure is just below $100 \mathrm{~mm}$. Hg. Occasional cases have, therefore, been included in which the final R.V. pressure has been as low as $80 \mathrm{~mm}$. $\mathrm{Hg}$, but this has reflected a lower pressure at operation than at cardiac catheterization before operation.

Infundibular resection was performed in 17 of these 60 patients in an attempt to reduce the right ventricular pressure, valvotomy only being carried out in the other 43 . Of these 17 patients the infundibular resection was closed in 7 (2 died) and open in 10 (3 died). The resection was successful in lowering the R.V. pressure in only 7 and of these 2 died (both had undergone open infundibular resection which is said to be more effective and therefore safer). Of the 10 in whom pressure conversion was not secured, 3 died ( 2 had had closed resection, 1 had open resection). The deaths in these 17 patients, therefore, totalled 5 (a mortality of 30 per cent).

Further, of the 43 patients who underwent valvotomy alone and were allowed to go through the post-operative period with a residual high R.V. pressure, 4 died (mortality 9 per cent). Two of these 4 had an open valvotomy; in 2 the valvotomy was closed. 

died.

Of the 60 patients 9 died; of the 22 aged over 20 years, 4 died; and of the 38 under 20 years, 5

Finally we come to a consideration of the 46 patients alive who were left with a residual high R.V. pressure ( 30 had valvotomy only, 7 had also infundibular resection). The results are shown in Table IX. It has not been possible to submit all these patients to catheterization, but in some

TABLE IX

Late Behaviour of Pressure in 46 Patients with a Residual High R.V.P.

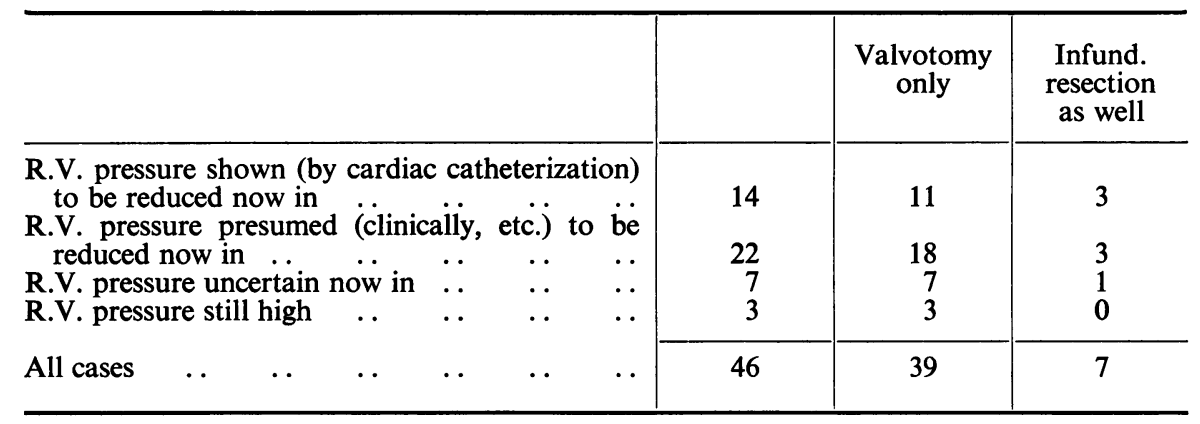

it has been considered by the cardiologist concerned, from a study of all the features, that there is now no evidence of residual pulmonary stenosis. The clinical findings in these patients have correlated so well with similar observations in those who have been shown by cardiac catheterization to have had a reversion of R.V. pressure, that the cardiologist has thought it a fair presumption that reversion has indeed occurred.

On this basis the right ventricular pressure is now no longer raised in 36 out of 46 patients: of these 36, valvotomy only had been done in 29 , and in 6 an infundibular resection had also been done. The pressure remains high in 10: in one of these a closed infundibular resection had also been done.

Of the 46 survivors of this study, 4 have since undergone further operation for open correction of residual infundibular stenosis, 2 of them did not survive operation and neither did another patient who had a preliminary valvotomy elsewhere. Some of the others who still have a raised R.V. pressure will need a second operation.

I fear that these figures are confusing but I will attempt to make them easier by giving my conclusions based on them.

(1) The condition is common $(37.5 \%)$, both in children and in adults.

(2) It is serious (15 died) and just as serious in children as in adults.

(3) If treated by immediate infundibular resection the mortality can be high (5 out of 17).

(4) The mortality may still be high even when the R.V. pressure is completely lowered (2 died out of 7).

(5) Infundibular resection may fail to correct the high R.V. pressure. Among the 12 survivors it was corrected in 5 but uncorrected in 7 .

(6) The residual infundibular stenosis is likely to revert spontaneously (in 36 of 46 patients).

(7) In a proportion the R.V. pressure remains high (10 out of 46).

(8) This may be due to congenital organic stenosis or to acquired fixed stenosis.

(9) The mortality of secondary resection of the infundibular stenosis may be high.

I think these conclusions support my present policy of not performing a routine open infundibular resection when the R.V. pressure remains high after preliminary valvotomy. I feel that the patient has a better chance of surviving if the hypertrophic infundibular stenosis is left to regress spontaneously. If digital exploration of the outflow tract of the right ventricle from above discloses a degree of resistance that suggests organic fibrous stenosis rather than functional stenosis, I would, 
of course, favour immediate resection. At present I do not find it possible to separate out those patients in whom spontaneous regression will not occur and I prefer to leave this to observation. The fact that a residual pressure of over $100 \mathrm{~mm}$. $\mathrm{Hg}$ is more sinister still does not enable precise selection of cases that will not convert spontaneously. If a surgeon is unhappy about leaving a high right ventricular pressure in all cases, then it would be reasonable to take this arbitrary figure of $100 \mathrm{~mm}$. $\mathrm{Hg}$ as a dividing line, but he should realize that he is still exposing his patient to an extra risk by the ventriculotomy.

I do not suggest that my analysis supplies the final answer to this problem. I suggest, however, that instead of surgeons making a dogmatic statement that all such cases need immediate infundibular resection they should support their policy by a similar analysis of their actual results. I would recommend anyone interested in this aspect of pulmonary valve stenosis to be familiar with Johnson's important presentations and analysis of the hæmodynamic and other factors involved.

\section{Pure Infundibular Stenosis}

Hypertrophic or functional infundibular stenosis inevitably reminds us that organic, congenital infundibular stenosis can occur as an isolated lesion. When fibrous infundibular stenosis accompanies valve stenosis it may, rarely, be a congenital lesion. It may, also rarely, be an acquired state due to secondary fibroid changes occurring in a primarily functional stenosis.

Time does not permit me to deal with this condition more than briefly. I will make only the following comments. It is rare: whereas I have operated on 198 cases of pulmonary valve stenosis I have operated on only 17 cases of pure infundibular stenosis.

The diagnosis is frequently overlooked, even with cardiac catheterization, and the best method of recognition is usually an angiocardiogram. The stenosis, as with valvar stenosis, ranges from mild to very severe. A small ventricular septal defect may co-exist and may be recognized only at operation.

Only an open operation is permissible, for this alone allows free and meticulous resection of the stenosis and avoidance of the tricuspid valve mechanism, which is in danger. Although this can be done under hypothermia it is much safer to use total perfusion.

Even with careful open resection it may not be possible to achieve immediate relief of the high R.V. pressure exactly as in pulmonary valve stenosis. This is due to the same mechanism of secondary infundibular hypertrophy. In the same way spontaneous regression can occur over 1-2 years, eventually giving a normal R.V. pressure as is shown by the following case of a child aged $7 \frac{1}{2}$ operated on in 1957 (Table X).

TABLE $\mathbf{X}$

SPONTANEOUs Regression of Residual High R.V.P. AFTER INFUNDibular Resection

\begin{tabular}{|c|c|c|c|}
\hline Pressures & & P.A. & R.V. \\
\hline $\begin{array}{l}\text { At cardiac catheterization, before operation } \\
\text { At operation, before resection } \quad . . \\
\text { At operation, after resection } \quad . . \\
\text { At cardiac catheterization } 3 \text { years later. . }\end{array}$ & $\begin{array}{ll}\cdots & \cdots \\
\cdots & \cdots \\
\cdots & \cdots \\
\cdots & \cdots\end{array}$ & $\begin{array}{l}18 / 12 \\
24 / 9 \\
23 / 12 \\
29 / 11\end{array}$ & $\begin{array}{l}195 / 15 \\
209 / 15 \\
189 / 16 \\
31 / 1\end{array}$ \\
\hline
\end{tabular}

\section{Stenosis of Pulmonary Valve Ring}

Early in this lecture it was pointed out that pulmonary valvar stenosis is often associated with other congenital cardiac abnormalities; one of those mentioned was the small or severely stenosed valve ring. This is usually, perhaps inevitably, accompanied by a small pulmonary trunk. Stenosis of the actual valve ring has been encountered several times in this series and when a closed valvotomy technique was being used it was revealed by the difficulty in passing anything but a small sound 
through the ring into the pulmonary trunk. It must be emphasized that the condition is quite distinct from an infundibular stenosis. The following example was disclosed at an open operation and also illustrates the difficulties of relieving the condition.

S.R., a boy aged 9 years, was normal at birth but began to show some dyspnœa and cyanosis at one year. By four years the cyanosis was obvious, and a few months before he came for treatment he became deeply blue, very dyspnœic, and could no longer walk. Operation was performed under total heart-lung by-pass. A pressure withdrawal record would have been difficult owing to the very severe concentric hypertrophy of the right ventricle, but needle puncture revealed a R.V. pressure of $205 / 10 \mathrm{~mm}$. $\mathrm{Hg}$.

The valve stenosis was composed of three equal commissures with a central circular orifice $3.5 \mathrm{~mm}$. in diameter and surrounded by a thick rosette of small vegetations which seemed to fill the lumen. The three commissures were divided but it was still not possible to introduce a $4 \mathrm{~mm}$. bougie into the ventricle from above.

The outflow tract of the right ventricle was now opened, its wall being $1.5 \mathrm{~cm}$. thick. Immediately below the valve ring was a small infundibular chamber about $1.25 \mathrm{~cm}$. long and with its thin outer wall almost devoid of muscle. There was no true infundibular stenosis and almost no tissue to resect. When the pulmonary valve ring was inspected from below it was found to be only $2 \mathrm{~mm}$. in diameter and was full of vegetations continuous with those observed from above. The severe stenosis of the valve ring explained why entry from above was still impeded after valvotomy. The stricture at the ring was much more severe than the stenosis of the valve orifice. It was dilated by graded bougies and finally by gentle use of an expanding dilator but it was still too small. Accordingly three incisions were made into it, one at the site of each commissure; the expanding dilator was again used and this was followed by a $1.25 \mathrm{~cm}$. bougie and eventually the index finger could be passed.

After the ventricular incision had been closed, the heart took over well and the pressure and pulsation in the pulmonary trunk seemed adequate. A withdrawal record showed a pressure of $20 / 8 \mathrm{~mm}$. in the pulmonary trunk, and of $50 / 5 \mathrm{~mm}$. in the right ventricle. The final right ventricular pressure, taken by needle, was $68 / 5 \mathrm{~mm}$. Hg. Recovery was complicated by rather prolonged right ventricular failure as shown by raised venous pressure and fluid retention, but this ultimately resolved satisfactorily.

\section{The Myocardial. Factor in Pulmonary Valve Stenosis}

I have told you something of the mortality of the surgical treatment of pulmonary stenosis and have mentioned briefly an assessment of the clinical results as presented by Campbell. It should be obvious to you that by modern open techniques the pulmonary valvotomy can be a precise, definitive procedure that should be capable of giving complete relief of the actual valvar stenosis in almost every case. It does not follow that the cure is thus complete, because other and more complex factors are involved, most of which are essentially myocardial in origin and nature. A good example is the complex state produced by hypertrophic infundibular stenosis which has just been presented and profoundly influences mortality and later clinical results.

This, indeed, introduces what I wish to make my closing theme and indeed my main message from my experiences in the surgical treatment of pulmonary stenosis. If a surgeon imagines that his task begins and ends with the operation on the valve then he is ignorant of all the implications of this disease. The surgical treatment, as opposed to the incident of the operation itself, must embrace what is happening to the patient and to his heart in the years before operation; what the factors are that influence the actual course of the operation, and what secondary disturbances must be taken into account in the immediate and later post-operative period. These considerations apply, of course, to all cardiac operations; I merely take pulmonary stenosis as supplying a particularly convenient example of them. Without respecting these considerations, the cardiac surgeon is a mere operator.

Of the various secondary features consequent on the pulmonary stenosis the most important are those acting through the myocardium and I wish to deal with two observations made on the later clinical course of these patients. Both, I consider, are fundamental.

First, our chairman today, Dr. Maurice Campbell, writing in 1959 on a clinical study of 64 patients after valvotomy discusses improvement in the electrocardiogram. In good result cases he finds that the right ventricular preponderance and strain pattern may disappear completely. This change may take place within a year, although in cases in which relief of the valvar stenosis has been 
replaced by a secondary hypertrophic infundibular stenosis, improvement is slower and may continue over as long as four years. In general, however, regression occurs unless there is residual organic pulmonary stenosis. He then considers the influence of age and observes that in patients in the late teens or over 20 years of age the improvement may be modified: the features of right ventricular preponderance may recede but the signs of right ventricular strain as shown by the T-wave inversion may not recede. Although it may be difficult to disentangle the factors of age and of inadequate relief of the stenosis, there is little doubt that the older the patient, the more difficult it is to achieve correction of the T-wave inversion. That this $\mathrm{T}$-wave inversion can represent functional changes is evident because it can be reversed by a successful operation. Campbell points out that we know equally that it can be due to permanent damage to the muscle of the ventricle: the changes usually consist of diffuse replacement fibrosis of irreversible nature. That this is influenced by age is reasonable and acceptable, especially as these changes are common after 20 and uncommon before this age (Allanby and Campbell, 1949).

Age is, however, not the only factor, for permanent changes can be seen in young children in whom complete relief of their stenosis has been achieved by the operation, but the original obstruction was very severe and had clearly caused myocardial damage. In other words youth does not necessarily protect the myocardium from irreversible changes.

Important corroboration of this is given by Johnson's recent work presented to the British Cardiac Society in which he reports that he has found that increase in cardiac output is abnormally small in many cases of pulmonary stenosis, both before and after valvotomy; and even when it is normal it is achieved abnormally. Persistence of abnormal response after complete relief of the stenosis and even after regression of the right ventricular hypertrophy indicates that another mechanism is involved other than the difficulty of ejection through the valvar stenosis. He finds evidence of increased resistance of the right ventricle to filling and suggests that this is due to permanent myocardial changes, most probably fibrotic.

The surgeon who actually handles the ventricular muscle at operation needs no convincing of the probability of permanent secondary changes having occurred when severe disease has been present for many years. The quality of the muscle is tough, it is more rigid, it is thicker, and when cut into it is obviously more fibrous. If cardiac massage is needed the rigid, inelastic quality is even more evident.

These observations of Campbell and of Johnson serve as factual verification of the postulate that must guide us in advising operation in cases of heart disease, at any rate of the obstructive type. They emphasize that it is unsatisfactory and dangerous to postpone operation in any case in which important obstruction is present. They emphasize the danger that exists in children for in them the power of ventricular hypertrophy is so great that severe obstruction may be present and yet symptoms may be absent. They may pay a high price for this youthful power of hypertrophy. Not only is severe obstruction overlooked or ignored in children, but they may even be encouraged to indulge in all forms of effort under the mistaken idea that they can do so without harm to their myocardium. Sir James Mackenzie is said to have stated that a child will never do himself harm by his own exertions: there is no doubt that this is utterly wrong.

It is essential that we should recognize the silent peril besetting these patients and that we strive to recognize and to measure the presence of significant obstruction and relieve it as soon as possible before permanent changes have occurred in the myocardium-changes that may occur even in a young child.

Another feature that indicates permanent myocardial changes is persistence of cardiac enlargement on radiography. Even though the heart size is smaller and even though right atrial enlargement has receded, the shadow of the ventricular mass may still be so large as to suggest residual stenosis. This may be supported by imperfect resolution of electrocardiographic changes. However, the clinical result may be excellent and complete relief of the stenosis is verified by cardiac catheterization. The persistence of cardiac enlargement is an indication of a damaged myocardium 
and it is in just this type of case that a subnormal cardiac output and poor response to exercise is demonstrated by Johnson's work.

The evidence that permanent myocardial damage to the right ventricle occurs can be summarized as below.

(1) Hypertrophic infundibular obstruction.

(2) Heart still large on radiograph.

(3) Electrocardiogram still shows T-wave inversion, etc.

(4) Little or no improvement in cardiac output, and no increase with exercise.

(5) Incomplete clinical recovery.

It is widely believed that Sir James Mackenzie, and certainly Sir Thomas Lewis, taught against the importance of valve disease and emphasized the over-riding importance of the myocardium itself. Sir Thomas Lewis certainly wrote "It is probable that the reason why valve disease is significant is not to be found mainly in the burdens that it imposes upon the muscle, but mainly in associated disturbances that come with the valve disease and from a common source. The heart displaying disease of its valves has usually been the seat of inflammatory process or of degenerative change." And again "Surgical attempts to relieve cases of mitral stenosis have so far failed to give benefit. I think they will continue to fail, not only because the interference is too drastic, but because the attempt is based upon what, usually at all events, is an erroneous idea, namely that the valve is the chief source of the trouble."

Certainly in my early efforts to establish mitral valvotomy I was met by much opposition based essentially on this doctrine. I am not sure that it was not exploited, by some psychological twist, to justify the laisser faire attitude that existed.

That Mackenzie emphasized the importance of the myocardium is certain, but I have been unable to find in his writings anything quite so forthright as Lewis's remarks against the primary importance of valve disease. His presentation of the basic importance of the myocardium in the efficiency of the heart is clear and impressive. His comment on "compensation" is especially acceptable. "Here I want to point out that hypertrophy, due to any morbid cause, invariably indicates an inefficient heart. I want you to grasp this, as there has come into use a term which is often used in a manner distinctly misleading. I refer to the term compensation. The use of this term is characteristic of much that is vague and unscientific in medicine ... If a patient has hypertrophy which is not physiological his power of response is limited."

Lewis's emphasis on the usual presence and importance of myocardial damage in association with valvar disease is, of course, correct and is only too often overlooked today when cardiac surgery is liable sometimes to direct too much attention to the valve lesion. Nevertheless, Lewis erred in negating the basic importance of a severe valve lesion. It may be that both he and Mackenzie were influenced by the impossibility of successful relief of valve disease by operation. Certainly their writings are dominated by acquired heart disease and their experience in congenital heart disease was scanty. If they had observed cases of pulmonary stenosis as carefully and as frequently as they studied cases of rheumatic and other forms of acquired heart disease, they would inevitably have modified their views on the relative importance of the primary valve lesion and of the state of the myocardium.

In congenital heart disease we have no evidence that the myocardium is affected by primary disease equally with the valve. The presumption is that the valve lesion is primary and that the diseased or degenerate state of the myocardium is entirely secondary to the valve obstruction. We have, therefore, in congenital heart disease a means of apportioning the relative importance of the valve lesion and the myocardial lesion. We can realize that the one arises from the other. I am sure that both Mackenzie and Lewis, had they been familiar with our greater experiences of congenital heart disease today, would have had no difficulty in accepting and teaching this. Their thoughts and knowledge and writings on the subject of the importance of the myocardium as the final determining factor of the clinical course and prognosis in heart disease apply just as strongly today to pulmonary stenosis as they did when they taught about acquired heart disease. Just as 
they tended to mark down the importance of the valve lesion, so there is a danger today that we do not attribute enough importance to the state of the myocardium in our own management of cases of congenital heart disease and especially of pulmonary stenosis. The state of the myocardium is paramount in all conditions of the heart.

\section{SUMMARY}

Experiences are presented in the treatment of 198 patients with pulmonary valve stenosis.

A brief survey is made of the incidence of the condition, morbid anatomy, clinical significance, and indications for operation.

The significance of cyanosis is discussed: of the 198 patients 74 were cyanosed, 124 were not. The proportion with cyanosis is less than it was initially. In general, it indicates a more severe lesion. The need for closure of the atrial communication is discussed: although not essential in most cases, closure is certainly preferable.

Closed pulmonary valvotomy is presented and it is shown that the results have been very satisfactory. However, the general principle of the superiority of open heart surgery applies in this condition, and the closed operation should be displaced by the open procedure except possibly in very poor risk cases, and more particularly in severely cyanosed infants. There were 8 deaths in 107 cases.

Open valvotomy is discussed and it is pointed out that most cases can be operated on more simply and more efficiently under hypothermia than under total heart-lung by-pass, except when the case is complicated or in the presence of cyanosis. There were 5 deaths in 84 cases.

The problem of persistent high right ventricular pressure after valvotomy is presented and discussed. This is one of the complex and difficult problems of operation for pulmonary stenosis. In most cases it is due to secondary hypertrophic infundibular stenosis. Occasionally the infundibular stenosis is fibrous and congenital, and sometimes a functional stenosis may undergo permanent fibrous changes.

We do not know yet what is the best management for these cases. The suggestion that routine infundibular resection should be done is not acceptable on the available evidence. Indeed evidence is put forward that this may carry an undesirably high mortality. Certainly in most cases spontaneous regression of muscular hypertrophy occurs over 1-2 years with spontaneous reversion of the high right ventricular pressure.

Spontaneous reversion of pressure occurred in 36 out of 46 patients. Several of the 10 in whom the pressure is still variably raised may require secondary infundibular resection, but not all of them. It is necessary, if this problem is to be satisfactorily settled, that other surgeons should present a careful analysis of their cases and refrain from dogmatizing until this is done.

Pure infundibular stenosis, a much rarer condition than valvar stenosis, is briefly discussed. Open operation under total body perfusion is obligatory.

It is not possible to understand the natural history and problems of pulmonary stenosis if only the valve stenosis is considered. Of great importance is the myocardial factor. This becomes increasingly important with the severity of the stenosis and the duration of the disease. Permanent myocardial damage may exist even in the young, and is usual after the late teens. Even after a complete relief of valve stenosis the prognosis can be adversely affected by these myocardial changes.

The significance of the myocardial factors underlines the need for early operation in almost all cases.

I cannot end this lecture without acknowledging the debt I owe to all my colleagues and assistants who have shared the management and treatment of these 198 cases of pulmonary valve stenosis. In addition to Dr. Maurice Campbell at Guy's Hospital, Dr. Paul Wood has asked me to operate on many patients at the Brompton Hospital and from the National Heart Hospital. Cardiac catheterization studies have been indispensable and I have been privileged to enjoy the very highest quality of work therein from a whole succession of Senior Registrars and Research Fellows. They will forgive me if I do not mention them all by name, just as I cannot name individually all those others without whom this series of heart operations would not have been possible. 


\section{REFERENCES}

Abbott, Maude (1936). Atlas of Congenital Heart Disease. New York.

Allanby, K. D., and Campbell, M. (1949). Guy's Hosp. Rep., 98, 18.

Blount, S. G., McCard, M. C., Mueller, H., and Swan, H. (1954). Circulation, 10, 161.

Brock, R. C. (1955). Guy's Hosp. Rep., 104, 356.

Bromley, L. L. (1958). Unpublished communication to Association of Thoracic Surgeons, Great Britain.

Campbell, M. (1953). Brit. Heart J., 15, 462.

(1959). Brit. Heart J., 21, 415.

(1960). Brit. Heart J., 22, 101.

C, and Missen, G. A. K. (1959). Guy's Hosp. Rep., 108, 390.

Conolly, D. C., Lev, R., Kirklin, J. W., and Wood, E. H. (1953). Proc. Mayo Clin., 28, 65.

Edwards, F. R. (1960). Brit. Heart J., 22, 472.

Greene, D. G., Baldwin, E. D., Baldwin, J. S., Himmelstein, A., Rob, C. E., and Cournand, A. (1949). Amer. J. Med., 6, 24.

Hanson, J. S., Ikkos, D., Crafoord, C., and Ovenfors, C. (1958). Circulation, 18, 588.

Johnson, A. M. (1959a). Brit. Heart J., 21, 429. (1959b). Guy's Hosp. Rep., 108, 373.

Kittle, C. F., Batchelder, T. L., and Miller, D. R. (1960). A.M.A. Arch. Surg., 80, 39.

Lam, C. R. (1960). Second International Symposium of the Deborah Hospital; Congenital Heart Disease. Philadelphia.

Lewis, T. (1933). Diseases of the Heart. London. Pp. 147, 148.

Mackenzie, J. (1916). Principles of Diagnosis and Treatment in Heart Affections. London. P. 135.

Merlin, W. H., and Longmire, W. F. (1951). Surgery, 30, 41.

Potts, W. J. (1959). J. thorac. cardiovasc. Surg., 38, 317.

Taussig, H. B. (1943). Congenital Malformations of the Heart. New York.

Varco, R. L. (1951). Discussion of the paper by Merlin and Longmire (1951).

Waterston, D. J. (1960). Personal communication.

Wood, P. (1950). Brit. med. J., 2, 639 and 693. 